\title{
Analysis of parental factors and parent-child communication with pediatric patients referred for nitrous oxide administration in a rural community health center setting
}

Sean G. Boynes ${ }^{1 *}$, Mohammad Abdulwahab², Elizabeth Kershner ${ }^{3}$, Felisha Mickens ${ }^{1}$ and Amah Riley ${ }^{1}$

*Correspondence: seangboynes@hotmail.com

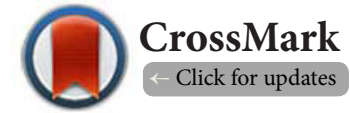

'Division of Dental Medicine, Care South Carolina, Society Hill, South Carolina, USA.

${ }^{2}$ Department of Surgical Sciences, Kuwait University, Kuwait City, Kuwait.

${ }^{3}$ Division of Behavior Health, Care South Carolina, Hartsville, South Carolina, USA.

\begin{abstract}
Objectives: The aim of this study was to identify and quantify likeness and difference in parent response to anxiety scale, dental knowledge, parent-child communication, and parental dental history. The objective is to determine if relationships exist with these parameters and the need for analgesia and/or sedation in their children.

Methods: A survey-based quality analysis was performed between June 2012 and May 2013 on 126 consecutive parents/guardians of children receiving nitrous oxide administration during dental care within CareSouth Carolina's Division of Dental Medicine Pediatric Dental Clinic (CSCDM).

Results: A total of 126 questionnaires were completed by the legal guardians of pediatric patients seen for dental care during the administration of nitrous oxide. The mean Corah's Anxiety Scale score corresponds to moderate anxiety. The mean score for the dental knowledge quiz was $2.98 \pm 1.13$ out of 5 (59.6\%).

The majority of parents responded that they discussed a previous dental visit with their child and 41.1\% described that visit to their child with negative connotations. A total of $50 \%$ of parents reported having a bad dental experience.

Conclusions: The results revealed a shared anxiety with dental care. Pediatric anxiety and fear of dental care is multifactorial and the parents have a significant role in its development. Parents of patients that required referral for a deeper form of sedation may have higher anxiety scores, lower dental knowledge scores, and be more likely to describe a previous dental visit as negative. The communication process between the child-patient and parent can include negative connotations.
\end{abstract}

Keywords: Dentistry, behavior modification, public health, nitrous oxide, communication

\section{Introduction}

Most children are cooperative and accept the administration of dental care; however, some demonstrate behaviors that make delivering quality care difficult $[\mathbf{1 , 2}]$. These behaviors are usually related to fear and anxiety with the dental care visit. Anxiousness and phobia often result in additional care appointments or referral to a specialist. Within rural safety net dental programs, these additional appointments or referrals can serve as a barrier to care due to: lack of available specialists, limited transportation options, missed opportunities, and financial limitations [3-5]. This is augmented with capacity issues experienced by these types of programs, which often see demand out-pace supply [5]. Appropriately assigning a type of sedation to each patient's treatment plan is imperative in order to avoid losing an appointment and maximizing the patient experience $[6,7]$.

Anxiety and fear preventing patients from obtaining care has been explored in previous publications. These reports demonstrate that a significant portion of the population avoid needed care due to fear and apprehension $[8,9]$. The cause of dental fear and anxiety is multifactorial with some researchers proposing the following: association with previous adverse 
experiences, the influence of peers, maternal relationships, socioeconomic status, oral health status, oral pain, dental fear in the family, and the negative influence of parents [10-15].

The role of the parent in completing a successful pediatric dental visit should never be underestimated. Several studies have demonstrated that a parent's perception of the dental visit can severely impact the success a dentist has with the pediatric patient [13-16]. The parent's perception and ideas of the dentist directly influence the anxiousness and apprehension a child has with any dental visit [14]. As a means to quantify and identify characteristics affecting patient care and improve quality outcomes, the present investigation evaluated parental anxiety, parental dental knowledge, the parent's previous dental experience, and the self-reported communication process between the parent and child-patient during anxiolysis/nitrous oxide administration referral for behavior management in a rural community based dental program.

\section{Materials and methods}

After being deemed exempt from the CareSouth Carolina Clinical Review Board, a survey-based quality analysis was performed between June 2012 and May 2013 on 126 consecutive parents/guardians of children receiving nitrous oxide administration during dental care within CareSouth Carolina's Division of Dental Medicine Pediatric Dental Clinic (CSCDM). All parents/guardians included in this study were with patients internally referred for analgesia/sedation care due to behavior issues at time of examination and prophylaxis. According to his/her training, the referring dentist determined that nitrous oxide was warranted for the elimination of anxiety and apprehension to improve the patient experience. The dentists were trained at different dental schools and the average years of experience were approximately 7 years. A standardized questionnaire form was used to collect data from the parents/guardians who voluntarily became subjects of this survey. The questionnaire was completed and turned into the dental site designee. No identifiable parent/guardian, patient, or provider information is recorded.

The questionnaire form contains 16 questions including the following: Corah's anxiety scale; dental knowledge; perceptions of personal dental care and child's dental care; parent and patient's mood; and the parent/guardian-child communication process.

Data from the questionnaire form is entered into a JMP Statistical Discovery Software program for analysis. Quantitative evaluations were confined to standard summation, an estimation of means, and a valid percent for identified variables. Additional statistical analyses were performed using Pearson's chi square test and analysis of variance, with $\mathrm{P}<0.05$ considered significant.

\section{Results}

A total of 126 questionnaires were completed by the legal guardians of pediatric patients seen for dental care during the administration of nitrous oxide over a period of one year. The forms were most likely completed by the patient's mother (86.5\%) followed by the father (7.9\%); grandmother (4.7\%); and foster parent $(0.8 \%)$. The subjects completing the forms identified their race as the following: African American (69.0\%); Caucasian (20.6\%); mixed race: African American/Caucasian (8.7\%); Asian American (1.6\%). All patients receiving care were identified by attestation as being at least $150 \%$ below poverty guideline. The majority of the patients involved in this analysis were within their initial visits to the dentist with $68.3 \%$ having had their first dental visit within the year. In some cases nitrous oxide did not provide an adequate level of anxiolysis or analgesia to complete the planned treatment, in these cases the patients were referred to an appointment in which a deeper level of sedation or anxiolysis could be achieved either within CSCDM or by an outside specialist provider. Of the 126 cases involved in this survey, 16 (12.7\%) required referral to an additional appointment.

The first section of the survey form was comprised of Corah's Anxiety Dental Questionnaire [17]. As demonstrated in Table 1, the anxiety ratings used for this analysis include: a score of 9-12 is considered moderate anxiety; $13-14$ is considered high anxiety; and 15-20 is considered severe anxiety. The mean score for all respondents is $11.65 \pm 4.12$, which corresponds to moderate anxiety.

The second aspect to the survey involved five questions aimed at discerning basic dental knowledge. The five true or false questions are as follows: cavities will go away with proper brushing; teeth with cavities should only have fillings put in if the teeth hurt; you and your child should brush his/ her teeth once a day; you and your child should see the dentist for a regular check up once a year. The mean score of all respondents is $2.98 \pm 1.13$ out of five (59.6\%).

The parent/guardian was asked if they discussed the upcoming dental appointment with their child. The majority of respondents (88.9\%) stated yes. Of the 112 replying yes, further questions included a five point response (1-relaxed; 2-a little uneasy; 3-tense; 4-anxious; 5-so anxious that I broke out in a sweat or almost felt physically sick) to "how would you describe your feelings when you were discussing today's appointment with your child?"The mean response is $2.83 \pm 1.04$, which would signify uneasy to tense. The respondents were asked if they discussed a previous dental visit during their discussion with their child, as well as, to give a brief general explanation of how they described that visit: as a positive experience; as a positive experience but told him/her about a difficult appointment I had; as a negative experience but told him/her that their appointment would be much better; or as a negative experience. A large portion of subjects $(41.1 \%$, 46 respondents) gave a description that could be perceived with a negative connotation (considered any response with the exception of "as a positive experience"). In fact, 8.0\% (9 respondents) reported that they described their previous 
Table 1. Corah's dental anxiety scale.

Corah's Dental Anxiety Scale consists of a series of four multiple choice questions answered by the patient/subject to determine a rating based on individual question scoring. Each answer is given an individual score and then added to provide an anxiety rating $(\mathrm{a}=1, \mathrm{~b}=2$, $\mathrm{c}=3, \mathrm{~d}=4, \mathrm{e}=5$ ).

1. If you had to go to the dentist tomorrow for a check-up, how would you feel about it?

a. I would look forward to it as a reasonably enjoyable experience; b. I wouldn't care one way or the other; c. I would be a little uneasy about it; $d$. I would be afraid that it would be unpleasant and painful; e. I would be very frightened of what the dentist would do.

2. When you are waiting in the dentist's office for your turn in the chair, how do you feel?

a. Relaxed; b. A little uneasy; c. Tense; d. Anxious; e. So anxious that I sweat or almost feel sick.

3. When you are in the dentist's chair waiting while the dentist gets the drill ready to begin working on your teeth, how do you feel? a. Relaxed; b. A little uneasy; c. Tense; d. Anxious; e. So anxious that I sweat or almost feel sick.

4. Imagine you are in the dentist's chair to have your teeth cleaned. While you are waiting and the dentist or hygienist is getting out the instruments which will be used to scrape your teeth around the gums, how do you feel?

a. Relaxed; b. A little uneasy; c. Tense; d.Anxious; e. So anxious that I sometimes sweat or almost feel sick.

\begin{tabular}{ll}
\hline Anxiety rating & Description \\
\hline $9-12$ & Moderate anxiety but have specific stressors that should be discussed and managed \\
$13-14$ & High anxiety \\
$15-20$ & $\begin{array}{l}\text { Severe anxiety (or phobia). May be manageable with the Dental Concerns Assessment but might require the help of a } \\
\text { mental health therapist. }\end{array}$
\end{tabular}

dental visit to their child as a negative experience. A breakdown of response is provided in Table 2.

Parent respondents whom stated they had a previous bad experience at the dental office were asked to provide a specific description of what caused the appointment to be negative in nature. Respondents were not limited to one selection and had the option to provide write-in responses. This yielded a total of 141 responses by the 63 parents/guardians who completed this section. The most common marked selections were as follows: "The dentist's attitude, the way he/she treated me was in a negative way" $(24.1 \%)$ "I had significant pain during the procedure" (21.3\%); "I did not get numb and the dentist kept drilling anyway" (20.6\%); "Getting a shot" (19.1\%); and "I was in the dental chair too long" (6.4\%). The write-in comments included:"I was in the waiting room forever", "I had a lot of bleeding after my extraction and could not get in touch with the dentist when I went home", "The medicine she gave me made me sick", and "I had horrible bruising for days after the dental appointment". A complete list of parent reports is available in Table 3.

Evaluation of parent questionnaires from the group of

Table 2. Parent description of previous dental visit to their child prior to the child's dental visit with nitrous oxide administration.

\begin{tabular}{ll}
\hline Parent description & $\begin{array}{l}\text { Percentage of } \\
\text { response }(\mathbf{n}=\mathbf{1 1 2})\end{array}$ \\
\hline $\begin{array}{l}\text { "As a positive experience" } \\
\begin{array}{l}\text { "As a positive experience but told him/her } \\
\text { about a difficult appointment I had" }\end{array}\end{array}$ & $58.9 \%$ \\
$\begin{array}{l}\text { "As a negative experience but told him/ } \\
\text { her that their appointment would be much } \\
\text { better" } \\
\text { "As a negative experience" }\end{array}$ & $13.5 \%$ \\
\hline
\end{tabular}

Table 3. Parents description of a personal bad experience with a dental visit in the past.

\begin{tabular}{|c|c|}
\hline Description & *\% Reported \\
\hline $\begin{array}{l}\text { "The dentist's attitude, I was treated in a negative } \\
\text { way" }\end{array}$ & $24.1 \%$ \\
\hline "I had significant pain during the procedure" & $21.3 \%$ \\
\hline $\begin{array}{l}\text { "I did not get numb and the dentist kept drilling } \\
\text { anyway" }\end{array}$ & $20.6 \%$ \\
\hline "Getting a shot" & $19.1 \%$ \\
\hline "I was in the dental chair too long" & $6.4 \%$ \\
\hline $\begin{array}{l}\text { "The dental hygienists attitude, I was treated in a } \\
\text { negative way" }\end{array}$ & $3.5 \%$ \\
\hline $\begin{array}{l}\text { "The receptionists attitude, I was treated in a } \\
\text { negative way" }\end{array}$ & $2.1 \%$ \\
\hline Additional write-in descriptions & $2.8 \%$ \\
\hline
\end{tabular}

${ }^{\star}$ Multiple answers were given and resulted in 141 responses by 63 parents.

patients requiring referral for deeper sedation care or to a pediatric dental specialist providing sedation $(n=16)$ was also completed. The mean Corah Anxiety Score (CAS) of this group was 15.52 \pm 3.31 (High Anxiety) and the mean dental knowledge score was $1.90 \pm 1.26$ out of $5(38.0 \%)$. A total of 13 of the 16 parents reported discussing the upcoming appointment with their child. The mean response in describing their feelings while talking to their child was $3.17 \pm 1.29$ which signifies tense. When further asked how they described their previous dental visit to the child-patient, the majority $(61.5 \%$, 8 reports) of referral group parents reported a description that could be perceived with a negative connotation. Of the 16 total referral group reports, $75.0 \%$ reported having a previous bad experience at the dentist office. Due to the small sample size statistical significance $(p<0.5)$ was not met when comparing the referral group to the rest of the study population. This should be considered a weakness of this 
Boynes et al. Oral Biology and Dentistry 2014,

http://www.hoajonline.com/journals/pdf/2053-5775-2-10.pdf

doi: $10.7243 / 2053-5775-2-10$

analysis; however, the information can be used to provide snapshot information.

\section{Discussion}

The results of this analysis revealed shared dental anxiety between parents and their children. The mean CAS for this parent population represented a level of moderate anxiety (11.65 \pm 4.12$)$. This finding corresponds to previous published reports that found a link between parents' anxiety and anxiety response in children $[\mathbf{1}, 3,19]$. It should also be noted that the parents of the children requiring a deeper level of sedation for treatment completion appear to have a higher level of anxiety (CAS: $15.52 \pm 3.31$ ). Further research may be warranted with a larger sample population.

The causes of dental fear are varied and most likely associated with a previous negative experience, socioeconomic status, oral pain, social environment, and/or parental influence [10-15,19]. One of the more accepted theories, Rachman's Model of Fear Acquisition proposes that fear is acquired through three possible pathways: classical conditioning, modeling, and the transmission of negative information by significant others [20]. A unique aspect to this analysis involves the information obtained relating to the parent-child communication process for dental visits. A significant portion (41.1\%) of the parents discussed a dental visit in a negative connotation to their children, thus allowing procurement of fear.

When parents or guardians deliberately instill fear and stress in children, they usually do so in order to attain one or two behavioral results. Oftentimes, the parent is seeking to control a child's behavior. An example of this is the parent who tells their child there is a monster in the basement, so the child will not attempt the stairs and risk injury. Or the parent in the doctor's waiting room, who tells the child to "behave or the doctor will give them a shot". Or, "If you don't behave for the dentist, he will use the drill on you". Such maladaptive parenting practices have been described as restrictive. Parents who tend to employ a restrictive style, are more likely to attempt to over control and to use punishment and criticism when their child faces a feared and unfamiliar situation [21]. While this strategy may gain behavioral compliance from the child, and even prevent injury, we now have a child who has learned to fear the dark, or the doctor and dentist. Consequently, when the time comes to go to the doctor or dentist, the child experiences anticipatory anxiety [22].

Another reason parents may instill fear, and thus anxiety in children, is to attempt to prepare the child for the worst that might happen. This is especially true for parents with their own negative history of dental visits. Parents want to protect their children and believe that by telling them about their own negative experiences, the child will be better able to cope with the potential pain and discomfort of dental procedures. These parents believe "forewarned is forearmed". While it is certainly true that if you know what to expect beforehand, you can be better prepared, a parent who has no positive frame of reference for their own dental experiences, may lack the skills necessary to prepare a child for a positive dental visit.

Evaluation of the parents' basic dental knowledge demonstrated inadequate oral health comprehension, scoring below $(59.6 \%)$ the desired $80 \%$ pass score. These findings reflect previous studies that report many parents lack adequate knowledge about oral health needs and oral health maintenance [23-25]. This lack of knowledge is higher in poorer and rural populations and may serve as a hindrance to achieving ideal oral health [24-26]. In addition, lack of dental knowledge has been associated with early childhood caries [26]. Several studies have found an association between deficient dental knowledge and increased dental anxiety $[10,27,28]$.

Further analysis of the questionnaires revealed that half (63 of 126) of the parents had a bad experience at previous dental visits. While the single most selected response was the parents' perception of negative treatment from the dentist $(24.1 \%)$, the majority of response correlated to local anesthesia administration (61.0\%). These selections demonstrated a negative patient experience report with anesthetic injections ("Getting a shot" [19.1\%]) and with failed or incomplete anesthetic administration ("I had significant pain during the procedure" [21.3\%]; "I did not get numb and the dentist kept drilling anyway" [20.6\%]). The injection process is often the first thing a person will associate with a dental visit and also serves as the number one way dentists are judged $[29,30]$. Unfortunately, the injection process is often associated with negative implications and pain experience [29]. Several parent respondents used descriptions that related to failed or incomplete anesthesia (41.9\%). Reported incidence of failed intraoral local anesthesia administration by dentists ranges from 2 to 20\% [3,30-33]. Inadequate or failed anesthesia at prior dental visits has been reported to acquiesce to dental anxiety and phobia $[\mathbf{8}, \mathbf{3 2}, \mathbf{3 4}, \mathbf{3 5}]$.

These findings reveal that key elements of the parents' parameters around dental interaction can translate to their child's dental visit experience. The attitudes of parents toward oral health care were shown to have a direct effect within the communication process concerning the child's dental visit and child fear/anxiety. Parental oral health attitudes have been explored in previous studies and found to effect home oral hygiene habits [36], recurrent decay rates [37], and overall oral health quality of life [38]. Additionally, a recently completed survey of diplomats of the American Board of Pediatric Dentistry demonstrated that pediatric dentists report parenting style changes during their practice lifetime they believe have adversely influenced child-patient behavior and caused changes in behavior management methodology within the pediatric dental care setting [39].

\section{Conclusion}

The results of this analysis revealed a shared anxiety with dental care between parents and their children. Pediatric 
anxiety and fear of dental care is multifactorial and the parents have a significant role in its development. The communication process between the child-patient and parent can include negative connotations.

\section{Competing interests}

The authors declare that they have no competing interests.

Authors' contributions

\begin{tabular}{|l|c|c|c|c|c|}
\hline Authors' contributions & SGB & MA & EK & FM & AR \\
\hline Research concept and design & $\checkmark$ & -- & -- & -- & -- \\
\hline Collection and/or assembly of data & $\checkmark$ & $\checkmark$ & -- & $\checkmark$ & $\checkmark$ \\
\hline Data analysis and interpretation & $\checkmark$ & $\checkmark$ & $\checkmark$ & $\checkmark$ & $\checkmark$ \\
\hline Writing the article & $\checkmark$ & $\checkmark$ & $\checkmark$ & $\checkmark$ & $\checkmark$ \\
\hline Critical revision of the article & $\checkmark$ & $\checkmark$ & $\checkmark$ & -- & -- \\
\hline Final approval of article & $\checkmark$ & $\checkmark$ & $\checkmark$ & $\checkmark$ & $\checkmark$ \\
\hline Statistical analysis & $\checkmark$ & $\checkmark$ & -- & -- & -- \\
\hline
\end{tabular}

\section{Acknowledgement}

The authors would like to acknowledge the exemplary assistance of Ms. Taylor Horne with patient relations and scheduling.

\section{Publication history}

Editor: Mabel M. R. Cordeiro, Federal University of Santa Catarina, Brazil.

EIC:Thimios A. Mitsiadis, University of Zurich, Switzerland. Received: 05-Oct-2014 Final Revised: 06-Nov-2014

Accepted: 21-Nov-2014 Published: 28-Nov-2014

\section{References}

1. Fields H, Machen JB, Chambers WL and Pfefferle JC. Measuring selected disruptive behavior of the 36- to 60-month-old dental patient. Part II: Quantification of observed behaviors. Pediatr Dent. 1981; 3:257-61. | Pdf | PubMed

2. Lawrence SM, McTigue DJ, Wilson S, Odom JG, Waggoner WF and Fields HW, Jr. Parental attitudes toward behavior management techniques used in pediatric dentistry. Pediatr Dent. 1991; 13:151-5. | Pdf | PubMed

3. Boynes SG, Riley AE, Milbee S, Bastin MR, Price ME and Ladson A. Evaluating complications of local anesthesia administration and reversal with phentolamine mesylate in a portable pediatric dental clinic. Gen Dent. 2013; 61:70-6. | Article | PubMed

4. Byck GR, Walton SM and Cooksey JA. Access to dental care services for Medicaid children: variations by urban/rural categories in Illinois. $J$ Rural Health. 2002; 18:512-20. | Article | PubMed

5. Norris JB, Kumar $\mathrm{C}$ and $\mathrm{Chard} \mathrm{S}$ et al. An empirical investigation into factors affecting patient cancellations and no-shows at outpatient clinics. Decision Support Systems. 2014; 57:428-443. | Article

6. Nelson T and Nelson $\mathrm{G}$. The role of sedation in contemporary pediatric dentistry. Dent Clin North Am. 2013; 57:145-61. | Article | PubMed

7. Milgrom P, Heaton LI and Newton IT. Different treatment approaches in different cultures and health care systems. Cognitive Behavioural Therapy for Dental Phobia and Anxiety. Ames, IA Wiley-Blackwell. 2013.

8. Sokolowski CJ, Giovannitti JA, Jr. and Boynes SG. Needle phobia: etiology, adverse consequences, and patient management. Dent Clin North Am. 2010; 54:731-44. | Article | PubMed

9. Dionne RA, Gordon SM, McCullagh LM and Phero JC. Assessing the need for anesthesia and sedation in the general population. J Am Dent Assoc. 1998; 129:167-73. | Article | PubMed

10. Milsom KM, Tickle M, Humphris GM and Blinkhorn AS. The relationship between anxiety and dental treatment experience in 5-year-old children. Br Dent J. 2003; 194:503-6. | Article | PubMed

11. Rachman S. Fear and Courage, $2^{\text {nd }}$ ed. New York; Freeman. 1990.

12. Majstorovic $M$ and Veerkamp JS. Relationship between needle phobia and dental anxiety. J Dent Child (Chic). 2004; 71:201-5. | Article | PubMed

13. Oliveira MM and Colares V. The relationship between dental anxiety and dental pain in children aged 18 to 59 months: a study in Recife, Pernambuco State, Brazil. Cad Saude Publica. 2009; 25:743-50. | Article I PubMed

14. Baier K, Milgrom P, Russell S, Mancl L and Yoshida T. Children's fear and behavior in private pediatric dentistry practices. Pediatr Dent. 2004; 26:316-21. | Article | PubMed

15. Klingberg G, Berggren U, Carlsson SG and Noren JG. Child dental fear: cause-related factors and clinical effects. Eur J Oral Sci. 1995; 103:40512. | Article | PubMed

16. Caraciolol $\mathrm{G}$ and Colares V. Prevalencia de medo el ou ansiedade relacionado a visita ao dentist em criancas com 5 anos de idade na cidade do Recife. Rev Odonto Cienc. 2004; 46:348-353. | Article

17. Corah NL, Gale EN and Illig SJ. Assessment of a dental anxiety scale. J Am Dent Assoc. 1978; 97:816-9. | Article | PubMed

18. Milgrom $P$, Weinstein $P$ and Heaton $L$. Treating fearful dental patients: A patient management handbook ( ${ }^{\text {rd }}$ Ed.). Seattle: Dental Behavioral Resources, 2009. | Book

19. Peretz B, Nazarian Y and Bimstein E. Dental anxiety in a students' paediatric dental clinic: children, parents and students. Int J Paediatr Dent. 2004; 14:192-8. | Article | PubMed

20. Rachman S. The conditioning theory of fear-acquisition: a critical examination. Behav Res Ther. 1977; 15:375-87. | Article | PubMed

21. Ginsburg GS and Schlossberg MC. Family-based treatment of childhood anxiety disorders. International Review of Psychiatry. 2002; 14:143-154. I $\underline{\text { Article }}$

22. Jellinek M, Patel BP and Froehle MC. Tips for parenting the anxious child. In: Bright Futures in Practice. Mental Health, Tool Kit. Arlington, VA: National center for Education in Maternal and Child Health. 2002; 2 96-97. | Article

23. Suresh BS, Ravishankar TL, Chaitra TR, Mohapatra AK and Gupta V. Mother's knowledge about pre-school child's oral health. J Indian Soc Pedod Prev Dent. 2010; 28:282-7. | Article | PubMed

24. Goodman HS, Macek MD, Wagner ML, Manz MC and Marrazzo ID. Selfreported awareness of unrestored dental caries. Survey of the Oral Health Status of Maryland Schoolchildren, 2000--2001. Pediatr Dent. 2004; 26:369-75. | Article | PubMed

25. Gussy MG, Waters EB, Riggs EM, Lo SK and Kilpatrick NM. Parental knowledge, beliefs and behaviours for oral health of toddlers residing in rural Victoria. Aust Dent J. 2008; 53:52-60. | Article | PubMed

26. Finlayson TL, Siefert K, Ismail Al and Sohn W. Psychosocial factors and early childhood caries among low-income African-American children in Detroit. Community Dent Oral Epidemiol. 2007; 35:439-48. | Article | PubMed

27. Rustvold SR. Oral health knowledge, attitudes and behaviors: Investigation of an educational intervention strategy with at-risk females. Dissertations and Theses. 2012; 612.| Pdf

28. Martino S. Oral health behavioral and social intervention research concepts and methods. J Public Health Dent. 2011; 71 Suppl 1:S2-6. | Article | PubMed Abstract | PubMed Full Text

29. Matthews DC, Rocchi A and Gafni A. Factors affecting patients' and potential patients' choices among anaesthetics for periodontal recall visits. J Dent. 2001; 29:173-9. | Article | PubMed

30. de St Georges J. How dentists are judged by patients. Dent Today. 2004; 23:98-9. | PubMed

31. Malamed SF. Is the mandibular nerve block passe? J Am Dent Assoc. 2011; 142 Suppl 3:3S-7S. | Article | PubMed

32. Wong MK and Jacobsen PL. Reasons for local anesthesia failures. J Am Dent Assoc. 1992; 123:69-73. | Article | PubMed 
Boynes et al. Oral Biology and Dentistry 2014,

http://www.hoajonline.com/journals/pdf/2053-5775-2-10.pdf

33. Kaufman $E$, Weinstein $P$ and Milgrom P. Difficulties in achieving local anesthesia. J Am Dent Assoc. 1984; 108:205-8. I Article I PubMed

34. Domoto $P$, Weinstein $P$, Kamo $Y$, Wohlers $K$, Fiset $L$ and Tanaka A. Dental fear of Japanese residents in the United States. Anesth Prog. 1991; 38:90-5. | PubMed Abstract | PubMed Full Text

35. van Wijk AJ and Hoogstraten J. Anxiety and pain during dental injections. J Dent. 2009; 37:700-4. | Article | PubMed

36. Rajab LD, Petersen PE, Bakaeen G and Hamdan MA. Oral health behaviour of schoolchildren and parents in Jordan. Int J Paediatr Dent. 2002; 12:168-76. | Article | PubMed

37. Sheehy E, Hirayama K and Tsamtsouris A. A survey of parents whose children had full-mouth rehabilitation under general anesthesia regarding subsequent preventive dental care. Pediatr Dent. 1994; 16:362-4. | PubMed

38. Jokovic A, Locker D and Guyatt G. How well do parents know their children? Implications for proxy reporting of child health-related quality of life. Qual Life Res. 2004; 13:1297-307. | Article | PubMed

39. Casamassimo PS, Wilson S and Gross L. Effects of changing U.S. parenting styles on dental practice: perceptions of diplomates of the American Board of Pediatric Dentistry presented to the College of Diplomates of the American Board of Pediatric Dentistry 16th Annual Session, Atlanta, Ga, Saturday, May 26, 2001. Pediatr Dent. 2002; 24:1822. | PubMed

\section{Citation:}

Boynes SG, Abdulwahab M, Kershner E, Mickens F and Riley A. Analysis of parental factors and parent-child communication with pediatric patients referred for nitrous oxide administration in a rural community health center setting. Oral Biol Dent. 2014; 2:10. http://dx.doi.org/10.7243/2053-5775-2-10 